\title{
Keep Learning in a pandemic: podcasts for learning development conversations and informal learning
}

\author{
Alicja Syska \\ University of Plymouth \\ Matthew Mesley \\ University of Plymouth
}

Keywords: podcasts; asynchronous learning; informal learning; conversation; Covid-19.

\section{The challenge}

The Learning Development (LD) team at the University of Plymouth comprises three LD advisors who support student learning across three respective faculties. As such, we form a constellation of separate entities with similar aims but individual approaches to what we do. Before March 2020, informal exchanges across our desks sufficed to maintain a sense of continuity in what we do as a team, but the Covid-19 pandemic induced move to working from home limited our ability to talk to each other. Initially, we ameliorated this situation by holding regular team meetings on Zoom. We discussed the pleasures and pains of online teaching, its challenges and frustrations, our accomplishments and discoveries, and all the observations we made in our workshops and tutorials with students. We soon realised that LD is more than what we teach, but students rarely get access to this informal aspect of our work. Indeed, those areas that could be particularly beneficial to students often fell outside the learning aims of our taught sessions or might only be touched upon in passing. A few questions thus presented themselves: how do we communicate these aspects of our practice? How do we continue the conversation of LD outside our teaching sessions in ways that are not bound by prescriptive or intentional approaches?

\section{The response}

Our answer was to do a podcast. Podcasting has been used in higher education since 2004 (Rosell-Aguilar, 2007) and in 2010 was predicted to become fully integrated into 
online learning (Edirisingha et al., 2010). This prediction was based on empirical evidence that demonstrated its positive impact not only on student learning but also on staff engagement. As an avid enthusiast of podcasts, one of us was already keen on developing this pedagogy, and the combination of this long-standing interest, the newly arisen need, and encouragement from other practitioners (Bohlman and Ross, 2021) emboldened us to take the plunge.

After making some initial decisions regarding hosting (in partnership), frequency (first weekly, then bi-weekly), and online platforms (iTunes, YouTube, and University intranet), much of what we decided to do in the podcast evolved gradually in the first few episodes. We would begin by introducing ourselves, the podcast, and the topic under discussion. After this, we might orientate the listener by situating the theme within its historical context or highlighting why the subject was worth discussing. It soon became apparent that it worked better if our conversation was not scripted, but instead guided by particular themes, topics, or even questions. This gave the episode a sense of structure or coherence, but we were careful not to be too strict here; opportunities for unprompted elements or reflections were common. We wanted to make listeners feel like they were listening to a conversation, which sought to inform and educate, but at the same time was not too didactic.

Other elements also arose organically; for example, early on, one of us suggested an object of the week segment, and from the beginning we also talked about how we might include guests. The latter we felt would be particularly important in offering listeners different perspectives, but also at a basic level it would help foster further connections within and beyond our team, and potentially challenge us to think about our practice in new and different ways. Only later would we discover communities of practice such as Podcasting for Pedagogic Purposes, which provide valuable advice and support.

We named the podcast Keep Learning to reinforce the message that learning happens all the time, and to emphasise its lifelong quality. It was clear that we were learning in action too; to paraphrase Tom Vanderbilt (2021), we did not know what we were doing but we were doing it anyway. We hoped that our openness to admit not to know all the answers would encourage students to let go of the tyranny of perfectionism and embrace the messiness of learning, especially in the new and challenging context of blended delivery. 


\section{Recommendations}

We admit that initially we created the podcast for ourselves, to fill the gaps that remote working opened in our practice. We did not publicise it to our students, there was no plan to use it strategically for LD instruction, and we had no fixed target audience (the podcast was not aimed at a particular cohort but at all interested students at the University of Plymouth, including independent learners). We also were naive to the statistics: out of over two million podcasts on Apple's directory, 25\% cease after episode one (Arendale, 2021), so it would take us time to discover that commitment and effective collaboration are key. The advantages of podcasting were, however, clear from the start. Due to their accessibility, we expanded our reach as learning developers beyond our workshops and tutorials. The podcasts humanised us and made our voices and faces familiar to those who would otherwise have few chances to meet us. We sometimes reacted to themes with different emotions or with humour, something that might ordinarily get lost in 'normal' LD conversations. In a way, we blurred the line between formal and informal learning and further amplified the concept of the third space (Whitchurch, 2008). The themed episodes also created a bank of resources on a number of varied topics, which students could return to in their own time.

We hope in future to augment and focus more on students' sense of belonging, for instance by involving students and recording for live audiences. We feel that the podcast has allowed us to communicate in a way that goes beyond academic instruction, but we could certainly build upon this further. In particular, we would like to explore how we might harness the podcast as a way of cultivating community (Wrather, 2016). In this respect, we can help to reduce post-pandemic anxiety and contribute to building a relational, more humane, educational ecosystem.

We do not hesitate in recommending podcasting as part of learning developers' practice and have some recommendations for new podcasters:

- have a partner to record with,

- don't be intimidated by technology,

- reach out to people beyond your team, 
- have a goal for each episode but don't script it,

- allow for emotion and humour,

- and don't fuss over editing - imperfections are permitted.

Podcasting is all about thinking outside the box and allowing ourselves to consider different ways of communicating our expertise and articulating our field. The latter is particularly important if LD is to become more formalised or academic - we need to still be able to talk in different registers and to connect to students in ways untethered from academic discourse.

\section{References:}

Arendale, D. (2021) 'Using Podcasting for Leader Development: Anywhere, Anytime', IAPL June Webinar, 10 June.

Bohlmann, J., and Ross, M. (2021) 'Building an Online Study Community through weekly podcasts at the University of Glasgow', ScotHELD Winter 2021 Conference, 22 January.

Edirisingha, P., Hawkridge, D. and Fothergill, J. (2010) 'A renaissance of audio: Podcasting approaches for learning on campus and beyond', European Journal of Open, Distance and E-Learning, 1. Available at:

https://openaccess.city.ac.uk/id/eprint/1339/1/A\%20Renaissance\%20of\%20Audio\%2 OPodcasting\%20approaches\%20for\%20learning\%20on\%20campus\%20and\%20bey ond article.pdf (Accessed: 15 June 2021).

Rosell-Aguilar, F. (2007) 'Top of the Pods - In Search of a Podcasting "Podagogy" for Language Learning', Computer Assisted Language Learning, 20(5), pp.471-492. https://doi.org/10.1080/09588220701746047.

Vanderbilt, T. (2021) Beginners: The Joy and Transformative Power of Lifelong Learning. London: Atlantic Books. 
Whitchurch, C. (2008) 'Shifting identities and blurring boundaries: The emergence of Third Space professionals in UK higher education', Higher Education Quarterly, 62(4), pp.377-396 https://doi.org/10.1111/j.1468-2273.2008.00387.x.

Wrather, K. (2016) 'Making "Maximum Fun" for fans: Examining podcast listener participation online', Radio Journal: International Studies in Broadcast \& Audio Media, 14(1), pp.43-63. https://doi.org/10.1386/rjao.14.1.43 1.

\section{Author details}

Alicja Syska is a Learning Development Advisor at the University of Plymouth, where she also teaches U.S. History and Visual Culture. She has a Ph.D. in American Studies from Saint Louis University, U.S.A., is a Senior Fellow of Advance HE, an ALDinHE Certified Leading Practitioner, and an SI/PASS supervisor. Her research interests include using visual methods in teaching, developing academic writing within disciplines, and fostering LD publishing and scholarship.

Matthew Mesley is a Learning Development Advisor at the University of Plymouth and currently works with students from the Faculty of Health. In a former life he was a medieval historian, and has written on medieval miracles, sex and gender, Jewish-Christian relations, and the Crusades. He has an MPhil from the University of Cambridge, a Ph.D. from the University of Exeter, and is a Fellow of Advance HE. 